\title{
ABSTRAK \\ PENINGKATAN KUALITAS HIDUP PASIEN KANKER YANG MENJALANI KEMOTERAPI MELALUI PENDEKATAN SPIRITUAL
}

\author{
Sulistyarini, Wahyu Dewi ${ }^{1}$, Safitri, Kiki Hardiansyah ${ }^{2}$, Palimbunga, Rutiyani ${ }^{3}$, Exlesia, Sarah $^{4}$, Rosidah, Siti ${ }^{5}$ \\ Program Studi Ilmu Keperawatan, Institut Teknologi Kesehatan dan Sains Wiyata Husada \\ Samarinda ${ }^{1,2,3,4,5}$ \\ *Korespondensi: kikihardiansyahsafitri@itkeswhs.ac.id, wahyudewis@itkeswhs.ac.id
}

\begin{abstract}
Kanker merupakan salah satu masalah utama kesehatan diberbagai negara. Diagnosis dan pengobatan kanker dapat menimbulkan berbagai masalah spiritual seperti marah kepada Tuhan, merasa ditinggalkan oleh Tuhan, merasa doa tidak pernah dikabulkan. Spiritualitas yang rendah juga dikaitkan dengan kualitas hidup yang rendah. Kualitas hidup memiliki struktur multidimensi yang mencakup fungsi fisik, mental, sosial dan kognitif. Kualitas hidup yang baik disebabkan karena individu memiliki penanganan religius koping yang positif seperti menganggap Tuhan sebagai sumber kekuatannya sedangkan penanganan religius koping yang negatif seperti mempertanyakan Tuhan dapat mempengaruhi kualitas hidup yang lebih buruk. Untuk dapat memiliki kesehatan mental dan perasaan positif, serta dapat menerima diri dari efek kemoterapi biasanya diperlukan metode pendekatan yang dapat membantu dalam menyelesaikan masalah yaitu dengan metode penyuluhan. Kegiatan Pendidikan kesehatan (penyuluhan) kesehatan mengenai pentingnya spiritual dalam meningkatkan kualitas hidup pasien kanker yang sedang menjalani kemoterapi ini ditujukan pada pasien kanker yang sedang menjalani kemoterapi dan pendamping pasien di rumah singgah kanker Kota Samarinda. Sebanyak kurang lebih 30 peserta yang terlibat dalam kegiatan ini. Hasil penyuluhan pasien kanker yang sedang menjalani kemoterapi dan pendamping pasien di rumah singgah kanker jalan delima 1, Kota Samarinda dengan total 30 orang dikategorikan berhasil karena terjadi peningkatan kualitas hidup setelah dilakukan penyuluhan dan dievaluasi setelah 4 minggu. Peserta penyuluhan terkait materi penyuluhan dan masyarakat tersebut mengharapkan ada kegiatan serupa dapat dilanjutkan dan dikembangkan menjadi kegaiatan yang rutin di rumah singgah kanker.
\end{abstract}

Kata kunci: Edukasi Kesehatan, Kualitas Hidup, Kanker dan Kemoterapi.

\section{PENDAHULUAN}

Kanker merupakan salah satu masalah utama kesehatan diberbagai negara (Siegel et al., 2015) dan penyebab utama kematian di negara berkembang (Torre et al., 2015). Kanker juga merupakan penyebab kematian nomer dua di dunia setelah penyakit kardiovaskuler dan diperkirakan insidens kanker pada tahun 2030 dapat mencapai 26 juta orang dan 17 juta diantaranya meninggal akibat kanker (Kemenkes RI, 2015). Prevalensi kanker di Indonesia sekitar 1,4 per 1000 penduduk atau sekitar 333.000 orang (Badan Penelitian dan Pengembangan Kesehatan, 2013). Menurut Kemenkes RI (2015) kanker menjadi penyebab kematian no 7 di Indonesia, hal ini disebabkan karena 70\% dari penderita kanker ditemukan dalam keadaan stadium lanjut.
Diagnosis dan pengobatan kanker dapat menimbulkan berbagai masalah spiritual seperti marah kepada Tuhan, merasa ditinggalkan oleh Tuhan, merasa doa tidak pernah dikabulkan (Gall \& Bilodeau, 2017). Masalah spiritual lainnya seperti tidak menerima dan menyangkal penyakit yang dialaminya dan takut akan mendekati kematian (Caldeira et al., 2017). Spiritualitas yang rendah juga dikaitkan dengan kualitas hidup yang rendah (Jafari et al., 2013).

Kualitas hidup memiliki struktur multidimensi yang mencakup fungsi fisik, mental, sosial dan kognitif (Manandhar et al., 2014). Kualitas hidup berhubungan dengan kesehatan fisik dan mental yang dapat memberikan perasaan positif, penerimaan diri, kebahagiaan, kesejahteraan dan hubungan interpersonal yang positif (Pratiwi, 2012). Spiritualitas dapat mempengaruhi kualitas 
hidup pada pasien dengan kanker (AlNatour et al., 2017). Kualitas hidup yang baik disebabkan karena individu memiliki penanganan religius koping yang positif seperti menganggap Tuhan sebagai sumber kekuatannya sedangkan penanganan religius koping yang negatif seperti mempertanyakan Tuhan dapat mempengaruhi kualitas hidup yang lebih buruk (Zamanian et al., 2015). Spiritualitas yang positif dapat dijadikan sebagai mekanisme koping positif untuk beradapatasi terhadap diagnosis dan pengobatan kanker (Khodaveirdyzadeh et al., 2016). Spiritualitas menjadi sangat penting ketika individu mengalami situasi yang mengancam nyawa oleh sebab itu percaya kepada Tuhan dapat mengatasi masalah yang ditimbulkan oleh penyakit kanker (Bhatnagar et al, 2017).

Adapun permasalahan mitra sebagai berikut :

1. Terdapat 15 pasien kanker stadium akhir yang sedang menjalani kemoterapi di rumah singgah kanker

2. Setelah dilakukan studi pendahuluan pada 3 pasien kanker stadium akhir di rumah singgah kanker mengatakan mengalami perubahan terkait dengan kualitas hidup selama menjalani kemoterapi apalagi jauh dari keluarga

3. 3 pasien tersebut juga menyampaikan bahwasanya kondisi kankernya yang stadium akhir mempunyai peluang bertahan hidup yang tidak lama

4. Adanya pendamping keluarga setiap pasien maupun pengelola rumah singgah kanker yang mendampingi pasien selama dirumah singgah kanker dalam menjalani proses kemoterapi

\section{METODE}

Kegiatan pengabdian kepada masyarakat di rumah singgah kanker jalan delima 1, Kota Samarinda dilaksanakan pada bulan November 2019 sampai Desember 2019. Sasaran kegiatan ini adalah pasien kanker yang sedang menjalani kemoterapi dan pendamping pasien di rumah singgah kanker . Kegiatan yang dilaksanakan meliputi pendekatan yang dapat membantu dalam menyelesaikan masalah yang ada yaitu dengan melakukan metode penyuluhan mengenai pentingnya spiritual dalam meningkatkan kualitas hidup pasien kanker yang sedang menjalani kemoterapi.

Kegiatan Pendidikan kesehatan (penyuluhan) kesehatan mengenai pentingnya spiritual dalam meningkatkan kualitas hidup pasien kanker yang sedang menjalani kemoterapi. Sebanyak kurang lebih 30 peserta yang terlibat dalam kegiatan ini.

Kegiatan pengabdian kepada masyarakat terbagi menjadi tiga tahap, yaitu persiapan, pelaksanaan, dan tahap monitoring. Berikut adalah rincian tiap tahapan yang akan dilaksanakan:

a. Tahap persiapan

1) Penyusunan program kerja penyuluhan

Penyusunan program penyuluhan dan program kerja agar kegiatan yang dilaksanakan menjadi lebih teratur dan terarah. Program ini meliputi semua hal-hal yang bersifat teknis, manajerial dan penjadwalan (time schedule).

2) Penyusunan materi penyuluhan

3) Persiapan sarana dan prasarana penyuluhan. Persiapan ini meliputi penyediaan sarana dan prasarana tempat penyuluhan.

4) Koordinasi lapangan. Koordinasi lapangan dilakukan oleh Tim.

5) Melakukan perijinan ke rumah singgah kanker selama 1 hari

6) Melakukan survei awal mengenai permasalahan mitra yang ada di rumah singgah kanker selama 1 hari

b. Tahap pelaksanaan

Penyuluhan bertujuan untuk menjelaskan lebih rinci tentang meningkatkan kualitas hidup pasien kanker yang sedang menjalani kemoterapi. Penyuluhan ini dipermudah dengan mendengarkan pemateri menyampaikan. Kegiatan ini akan dihadiri oleh pengelola rumah singgah, tim pengabdian kepada masyarakat STIKES WHS dan 
masyarakat yang akan mengikuti penyuluhan ini

c. Tahap Evaluasi

Tahap Monitoring dan Evaluasi. Monitoring dilakukan secara intensif oleh tim pelaksana setiap kegiatan berlangsung untuk memastikan agar pelaksanaan kegiatan dapat berjalan sesuai rencana. Evaluasi dilakukan sejalan dengan monitoring, sehingga jika ada kendala akan segera diselesaikan. Evaluasi dilakukan setiap tahap kegiatan, adapun rancangan evaluasi memuat uraian bagaimana dan kapan evaluasi akan dilakukan, kriteria, indikator pencapaian tujuan, dan tolok ukur yang digunakan untuk menyatakan keberhasilan dari kegiatan yang dilakukan.

\section{HASIL}

Gambaran peserta kegiatan ini adalah pasien kanker yang sedang menjalani kemoterapi dan pendamping pasien di rumah singgah kanker jalan delima 1, Kota Samarinda dengan total 30 orang. Pelaksanaan penyuluhan dilakukan dalam 1 (satu) hari. Sebelum dilakukan penyuluhan, seluruh peserta menjawab pretest, sebagai evaluasi penilaian.

Tabel 4.1 Hasil Penilaian Pre Test Kualitas Hidup Pasien Kanker yang Menjalani Kemoterapi

\begin{tabular}{|l|l|l|l|}
\hline No & $\begin{array}{c}\text { Kualitas } \\
\text { Hidup }\end{array}$ & $\begin{array}{c}\text { Jumlah } \\
\text { masyarakat } \\
\text { Hasil } \\
\text { Pretest }\end{array}$ & \% \\
\hline 1 & Kurang Baik & 10 & $66,7 \%$ \\
\hline 2 & Baik & 5 & $33,3 \%$ \\
\hline \multicolumn{2}{|l|}{ Jumlah } & & $100 \%$ \\
\hline
\end{tabular}

Tabel 4.1 menunjukkan sebagian besar kualitas hidup pasien kanker yang menjalani kemoterapi kurang baik. Sebanyak 66,7\% masyarakat dengan capaian kualitas hidup "kurang baik" dan pada katagori "baik" hanya $33,3 \%$. Selanjutnya dilakukan penyuluhan selama 5 (lima) jam dengan isi materi penyuluhan sebagai berikut:

a. Dampak kemoterapi dalam kehidupan sehari-hari

b. Pendekatan spiritual dalam meningkatkan kualitas hidup

Setelah pemberian penyuluhan selesai, 4 minggu selanjutnya setiap peserta dilakukan postest kembali dengan waktu yang sama pada saat pretest (15 menit). Pada proses penyuluhan sebagian besar peserta sangat aktif dan ada yang sharing mengalami pengalamannya dalam melakukan pendekatan spiritual.

Berikut adalah hasil rekapitulasi dari postest setelah penyuluhan:

Tabel 4.2 Hasil Penilaian Post Test Kualitas Hidup Pasien Kanker yang Menjalani Kemoterapi

\begin{tabular}{|l|l|l|l|}
\hline No & $\begin{array}{c}\text { Kualitas } \\
\text { Hidup }\end{array}$ & $\begin{array}{c}\text { Jumlah } \\
\text { masyarakat } \\
\text { Hasil Pretest }\end{array}$ & \% \\
\hline 1 & Kurang Baik & 3 & $80 \%$ \\
\hline 2 & Baik & 12 & $20 \%$ \\
\hline \multicolumn{2}{|l|}{ Jumlah } & 15 & $100 \%$ \\
\hline
\end{tabular}

Tabel 4. 2 menunjukkan adanya peningkatan kualitas hidup peserta, walaupun demikian masih ada peserta yang mempunyai nilai "kurang baik" (hanya 3 orang).

Tabel 4.3 Hasil Pencapaian dari nilai Pre Test dan Post Test

\begin{tabular}{|l|l|l|l|}
\hline No. & $\begin{array}{l}\text { Kualitas } \\
\text { Hidup }\end{array}$ & $\begin{array}{l}\text { \% Hasil } \\
\text { Pre test }\end{array}$ & $\begin{array}{l}\text { \% Hasil } \\
\text { Post } \\
\text { test }\end{array}$ \\
\hline 1 & Kurang Baik & $66,7 \%$ & $20 \%$ \\
\hline 2 & Baik & $33,3 \%$ & $80 \%$ \\
\hline
\end{tabular}

Perhitungan pencapaian keberhasilan penyuluhan dengan cara hasil postest dikurangi pretest, kemudian dijadikan nilai persen. Berdasarkan data diatas, penyuluhan pasien kanker yang sedang menjalani kemoterapi dan pendamping pasien di rumah singgah kanker jalan delima 1, Kota 
Samarinda dengan total 30 orang dikategorikan berhasil karena terjadi peningkatan kualitas hidup setelah dilakukan penyuluhan dan dievaluasi setelah 4 minggu.

\section{KESIMPULAN}

Akibat efek samping yang ditimbulkan dari kemoterapi membuat pasien mengalami masalah-masalah baik secara fisik dan psikologis yang membuat kualitas hidup pasien menjadi buruk. Maka dari itu dilaksanakan upaya promotif untuk meningkatkan kualitas hidup pasien dengan pendekatan spiritual yang dilakukan oleh dosen dan mahasiswa keperawatan ITKES Wiyata Husada Samarinda agar pasien dapat menerima keadaan yang dialami dan lebih memiliki semangat hidup.

\section{REFERENSI}

Wiksuarini, E., Rochmawati, E., \& Rahmah, R. (2018). Spiritualitas dan Kualias Hidup pada Pasien Kanker. DINAMIKA KESEHATAN: JURNAL KEBIDANAN DAN KEPERAWATAN, 9(2), 301-312.

Yusniarita, Y., Patroni, R., \& Ningsih, R. (2016). Pengaruh dukungan spiritual terhadap kualitas hidup penderita kanker payudara pasca kemoterapi. Jurnal media kesehatan, 9(2), 144-151. 